\title{
Effects of Moderate Intensity Physical Training in Neonatal Alloxan- Administered Rats
}

\author{
Carla Ribeiro*, Clécia Soares de Alencar Mota, Fabrício Azevedo Voltarelli, Michel Barbosa de Araújo, José Diego Botezelli, Camila \\ Aparecida Machado de Oliveira and Maria Alice Rostom de Mello
}

Department of Physical Education, São Paulo State University (UNESP), Rio Claro-SP, Brazil.

\begin{abstract}
Newborn rats ( 6 days old) received alloxan intraperitoneally $(A=250 \mathrm{mg} / \mathrm{kg} \mathrm{b} . \mathrm{w})$. Rats injected with vehicle (citrate buffer) were used as controls (C). After weaning, half of the animals were submitted to 1 hour/day, 5 days/week swimming and with supporting overload of $5 \%$ b.w. At 28 days, no significant differences were found among the groups in fasting glycemia and insulinemia. At 60 days, the fasting glycemia (30 min after oral glucose administration) was higher in alloxan than in controls groups and lower in the alloxan group submitted to training than in the correspondent sedentary group. The glucose tolerance of the alloxan rats was reduced in comparison to controls, both at 28 and 60 days, since the area under the blood glucose curve during the OGTT was higher in the alloxan than in the control. No difference was found among the groups both at 28 and 60 days in the HOMA index. However, a slight reduction was observed in the values of the trained groups suggesting slightly increased insulin sensitivity in the animals. These results suggest that this diabetes mellitus animal model presents interesting characteristics for the study of the role of the physical exercise in diabetes outcome.
\end{abstract}

Keywords: Neonatal rats; Alloxan; Diabetes mellitus; Physical exercise

\section{Introduction}

Diabetes is a group of metabolic disorders characterized by hyperglycemia resulting from the deficiency, partial or total, in insulin secretion or insulin action [1,2]. The type 1 diabetes mellitus (T1DM), or type 2 diabetes mellitus (T2DM) is a multifactorial autoimmune disease, which susceptibility is determined by a combination of genetic and environmental factors $[1,2]$. The disease is characterized by chronic hyperglycemia and by the development of specific vascular alterations [3]. In this diabetes type, there is a, T cell mediated destruction of the insulin secreting $\beta$ cells of the pancreatic islets. The destructive process leads to severe insulin depletion that requires exogenous insulin administration for glucose homeostasis maintenance $[1,4]$.

The type 2 diabetes is characterized by insulin resistance, which leads to a characteristic hyperglycemic picture [5]. T2DM represents about $90-95 \%$ [1] of all the diabetic populations and can be unchained by several factors such as the obesity, high calorie diet and lack of physical activity [6].

The regular practice of the physical exercise has been considered important in the treatment of T2DM, helping in the glycemic control $[7,8,9]$. On the other hand, there is little direct evidence in relation to the preventive effect of the exercise on the onset of the T2DM. Experimental models offer the opportunity for the study of this matter. Rats treated with streptozotocin in the neonatal period have long been used as chemical T2DM models [10]. However less is known about the neonatal alloxan diabetes model.

Kodama et al. [11] developed a neonatal diabetes model using alloxan. In this study, alloxan was administered in rats at the 2, 4 or 6 days of life. When analyzed at the 60 day of life, the rats which received alloxan at the 2 day of life presented blood glucose level in the fed state slightly higher than the control rats, while those who received the drug at the 4 and 6 days of life presented blood glucose level significantly higher than the control rats. The authors considered the model useful for studies on chronic diabetes complications.
However, according to the same authors, more studies are necessary to verify whether or not this model has the characteristics of T2DM.

Oliveira et al. [12] analyzed the fasting blood glucose levels as well as the glucose tolerance and insulin sensitivity of rats from both genders which were treated with alloxan at the 2 days of life at the 28,60 and 90 days of life. The fasting blood glucose level was not different from that found in control rats at any moment. Rats treated with alloxan presented glucose intolerance at the 30 and 60 days of life. This condition was spontaneously remised at the 90 days. Taken together, these data indicate that characteristics of the newborn alloxan treated rat model deserves further studies.

Therefore, the present study was designed to analyze the effects of physical training on the diabetes outcome in rats submitted to the neonatal alloxan application, to characterize an experimental model appropriate for studies on the role of exercise in diabetes prevention.

\section{Methods}

\section{Animals}

The studies were carried out on male Wistar rats, maintained in a room at $25 \pm 1{ }^{\circ} \mathrm{C}$ on a 12-h light-dark cycle, with free access to standard rat chow and water. All experiments with the animals were approved by the committee of ethics in animal research, Taubate University-CEEA/UNITAU, under protocol $n^{\circ}$ 019/08.

*Corresponding author: Carla Ribeiro, Avenue. 24 A, 1515, Bela Vista - Rio Claro -SP, CEP 13506-900, Institute of Biosciences, Department of Physical Education São Paulo State University (UNESP), Rio Claro-SP, Brazil, Tel: +55 1935264308 E-mail: Carla ef rc@yahoo.com.br

Received October 27, 2010; Accepted October 30, 2010; Published November 02, 2010

Citation: Ribeiro C, de Alencar Mota CS, Voltarelli FA, de Araújo MB, Botezelli JD et al. (2010) Effects of Moderate Intensity Physical Training in Neonatal AlloxanAdministered Rats. J Diabetes Metab 1:107. doi:10.4172/2155-6156.1000107

Copyright: ๑ 2010 Ribeiro C, et al. This is an open-access article distributed under the terms of the Creative Commons Attribution License, which permits unrestricted use, distribution, and reproduction in any medium, provided the original author and source are credited. 


\section{Animals' breeding}

For breeding, the harem method was used. Four females and one male were set overnight in collective cages. Breeding confirmation was made through the presence of spermatozoids in the vaginal smear in the following morning. The covered females were set in individual cages until pups' birth. Males were discarted.

\section{Neonatal alloxan administration}

At 6 days old, the male pups, with body weight of $11.9 \pm 1.2$ $\mathrm{g}$, received alloxan monohydrate injection (Sigma-Aldrich Inc., St Louis, MO, USA) dissolved in citrate buffer $0.01 \mathrm{M}, \mathrm{pH} 4.5(250 \mathrm{mg} / \mathrm{kg}$ body weight) intraperitoneally), after a 12 -h fast. As controls, sameold, vehicle-injected (citrate buffer) rats were used. Immediately, the pups were distributed in such a way that each mother suckled eight of them.

\section{Experimental groups}

At 28 days old, the animals were randomly divided into four groups and remained in treatment until 60 days old: sedentary controls (SC), citrate buffer-injected rats; (SA), sedentary alloxan-injected rats; (TC), citrate buffer-injected rats submitted to exercise and (TA), alloxaninjected rats submitted to exercise.

\section{Exercise training}

The exercise protocol consisted of swimming for $1 \mathrm{~h} \mathrm{day}{ }^{-1}, 5$ days week $^{-1}$, with a $5 \%$ body weight overload, in a swimming pool filled with water at $31 \pm 1{ }^{\circ} \mathrm{C}$, during 4 weeks. This exercise protocol was selected because in previous studies we demonstrated that it corresponds to moderate aerobic exercise training for rats [13].

\section{Assessments}

\section{Body weight and food and water intake}

All the animals had body weight and food and water intake recorded once a week.

\section{Blood glucose and insulin}

The confirmation of the diabetogenic effect of alloxan was made when the rats were 28 and 60 days old, by the determination of fasting (after a 12-h fast) and non-fasting (30 min after administration of glucose solution, $2.0 \mathrm{~g}[\mathrm{~kg} \text { body weight }]^{-1}$, into the stomach through a gastric catheter) blood glucose and insulin concentrations. Blood samples $(25 \mu \mathrm{l})$ were obtained from a cut at the tip of the tail. Glucose was determined by the glucose oxidase colorimetric enzymatic method (Laborlab Kit, Guarulhos, Sao Paulo, Brazil) and Insulin was determined by RIA [14].

\section{Oral Glucose Tolerance Test (GTTo)}

The test was performed after a 12-hour fast, with animals at 28 and 60 days of age. A first blood collection from the tip tail was performed (time zero 0 ) and a polyethylene gastric catheter was orally introduced up to the stomach and a glucose solution at $20 \%(2 \mathrm{~g} / \mathrm{Kg}$ of body weight) was administered. Blood samples were collected after 30, 60 and 120 minutes from the glucose administration with heparinized capillaries, calibrated to $25 \mu \mathrm{L}$, for glucose determination by the glucose-oxidase method (Laborlab Kit, Guarulhos, Sao Paulo, Brazil). The results were evaluated through the total areas under the serum glucose curves ( $\mathrm{AG}=\mathrm{mM} 120 \mathrm{~min}$ ) using the trapezoidal method [15] and the ORIGIN 6.0 software (1999).

\section{Insulin sensitivity}

In order to estimate the insulin sensitivity of the animals at 28 and 60 days of age, the Homeostasis Model Assessment index (HOMA-IR) was used. The insulin sensitivity HOMA index was calculated using the following formula:

Serum insulin in fast (pmol/L) X Blood glucose in fast (mmol/L) / 22.5 .

According to this method, high HOMA indexes indicate low insulin sensitivity (insulin resistance) [16].

\section{Exercise test}

In order to evaluate the effects of the training protocol on aerobic conditioning, a swimming effort test was accomplished in the last week of the experiment. The test lasted 20 minutes and blood samples $(25 \mu \mathrm{l})$ were collected in rest and every 5 minutes of exercise, from a cut at the tip of the tail of animals for lactate analysis. The blood lactate analysis was accomplished by an enzymatic method [17].

\section{Statistics}

The analysis of the data was performed using the student $t$ test (28 days data) or Analysis of Variance (Two-Way ANOVA) followed by test Post Hoc of Newman - Keuls (60 days data), using the STATISTIC 6.0 program. In all cases, the significance level was pre-fixed at $5 \%(\mathrm{p}$ $<0.05)$.

\section{Results}

The values corresponding to area under body weight curve of the animals from weaning ( 28 days) to the end of the experiment (60 days) are shown in (Figure 1). The analysis of variance indicated that the alloxan trained (TA) presented lower area under body weight curve than sedentary alloxan (SA) and trained control (TC). Moreover the trained groups lower body weight gain than corresponding sedentary groups.

\section{AREA UNDER BODY WEIGNTCURVE}

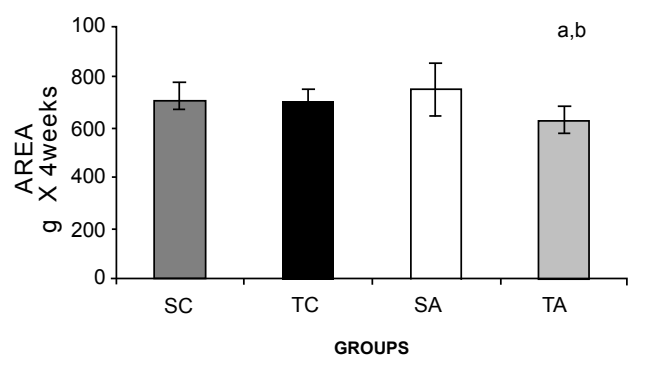

Figure 1: Area under body weight curve of the animals from weaning ( 28 days) to the end of the experiment ( 60 days). Results expressed as mean \pm standard deviation; $n=10$ animals per group. $S C=$ Sedentary control; Trained control =TC; Trained alloxan =TA; Sedentary alloxan =SA. (Two-way ANOVA, P<0,05) $\mathrm{a}=\mathrm{TC} \times \mathrm{TA} ; \mathrm{b}=\mathrm{SAx} \mathrm{TA} ; \mathrm{c}=\mathrm{SC} \times \mathrm{TC}$.

\begin{tabular}{|l|l|l|}
\hline 28 days & C & A \\
\hline Fasting Glycemia & $4.9 \pm 0.5$ & $4.7 \pm 0.5$ \\
\hline Glycemia, after overload of glucose & $9.3 \pm 1.1$ & $11.6 \pm 1.6^{*}$ \\
\hline Fasting Insulynemia & $61.2 \pm 14.0$ & $51.3 \pm 20.2$ \\
\hline Insulynemia after overload of glucose & $73.0 \pm 23.2$ & $151.9 \pm 6.7^{*}$ \\
\hline
\end{tabular}

Results expressed as mean \pm standard deviation; $n=8$ animals per group. $\mathrm{C}=$ control; $\mathrm{A}=$ alloxan * $\mathrm{T}$-Student, $\mathrm{P}<0.05$ in relation to $\mathrm{C}$.

Table 1: Glycemia (mmol/L) and insulynemia (pmol/L) after a $12 \mathrm{hs}$ fasting and 30 minutes after an oral glucose overload 28 days of old. 
Citation: Ribeiro C, de Alencar Mota CS, Voltarelli FA, de Araújo MB, Botezelli JD, et al. (2010) Effects of Moderate Intensity Physical Training in Neonatal Alloxan- Administered Rats. J Diabetes Metab 1:107. doi:10.4172/2155-6156.1000107

Page 3 of 5

(A)

AREA UNDER FOOD INTAKE CURVE

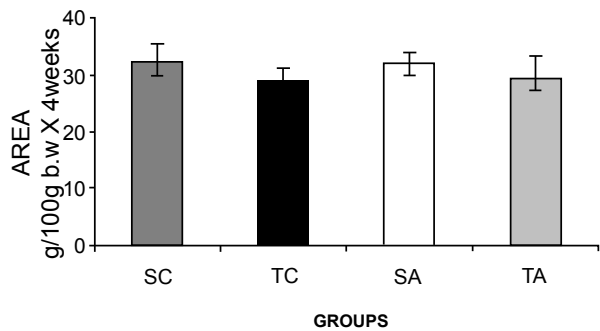

(B)

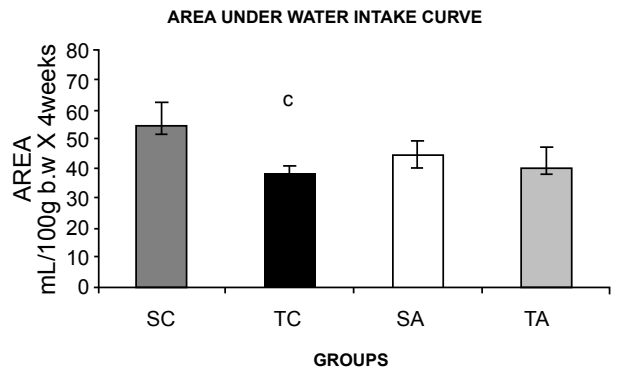

Figure 2A e 2B: Area under food (A) and water (B) intake curve of the animals from weaning ( 28 days) and to the end of the experiment ( 60 days). Results expressed as mean \pm standard deviation; $n=10$ animals per group. $\mathrm{SC}=$ Sedentary control; Trained control $=\mathrm{TC}$; Trained alloxan $=\mathrm{TA}$; Sedentary alloxan $=$ SA. (Two-way ANOVA, $\mathrm{P}<0.05$ ). $\mathrm{c}=\mathrm{SC}$ x TC.

(A)

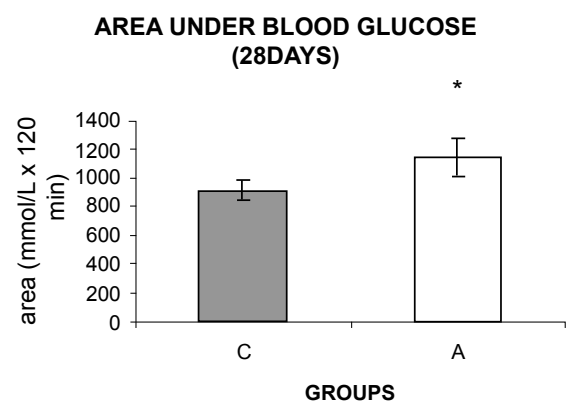

(B)

AREA UNDER BLOOD GLUCOSE (60DAYS)

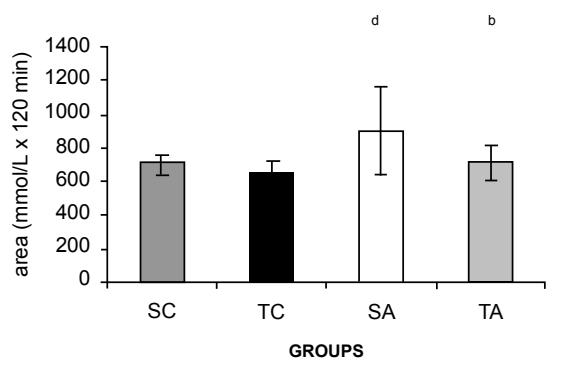

Figure 3A e 3B: Área under blood glucose curve during the glucose test (AG, $\mathrm{mmol} / \mathrm{L} \times 120 \mathrm{~min})$ of the animals at weaning $(A)(28$ days $C=$ control; $A=$ alloxan. *Student $T$-test, $P<0.05$ in relation to $C)$ at 60 days $(B)(C S=$ sedentary control; $\mathrm{CT}=$ Trained control; $\mathrm{AT}=$ Trained alloxan; $\mathrm{AS}=$ Sedentary alloxan. Two way ANOVA, $\mathrm{P}<0.05)$ Results expressed as mean \pm stantard; $\mathrm{n}=10$ animals per group. $b=S A x T A, d=S C x S A$.

\begin{tabular}{|l|l|l|l|l|}
\hline 60 days & SC & TC & SA & TA \\
\hline Fasting Glycemia & $5.5 \pm 0.4$ & $4.6 \pm 0.4^{\mathrm{c}}$ & $5.5 \pm 0.5$ & $4.4 \pm 03^{\mathrm{b}}$ \\
\hline $\begin{array}{l}\text { Glycemia,after } \\
\text { overload of glucose }\end{array}$ & $6.6 \pm 0.8$ & $6.0 \pm 1.9$ & $9.4 \pm 1.2^{\mathrm{d}}$ & $6.4 \pm 1.0^{\mathrm{b}}$ \\
\hline Fasting Insulynemia & $207.3 \pm 96.7$ & $210.8 \pm 84.6$ & $222.8 \pm 82.2$ & $164.5 \pm 30.8$ \\
\hline $\begin{array}{l}\text { Insulynemia after } \\
\text { overload of glucose }\end{array}$ & $\begin{array}{l}364.8 \pm \\
194.4\end{array}$ & $\begin{array}{l}216.0^{\mathrm{D}} \\
\pm 59.4^{\mathrm{c}}\end{array}$ & $367.5 \pm 75.2$ & $234.5 \pm 100.5^{\mathrm{b}}$ \\
\hline
\end{tabular}

Results expressed as mean \pm standard deviation; $n=8$ animals per group. $\mathrm{SC}=$ Sedentary control; Trained control $=T C$; Trained alloxan $=T A$; Sedentary alloxan =SA. (Two-way ANOVA, $P<0,05) b=S A x T A ; c=S C x$ TC; $d=S C x$ SA.

Table 2: Glycemia(mmol/L) and insulynemia (pmol/L) after a $12 \mathrm{hs}$ fasting and 30 minutes after an oral overload 60 days of old.

\begin{tabular}{|l|l|l|}
\hline Groups & 28 days & $\mathbf{6 0}$ days \\
\hline SC & $1.86 \pm 0.48$ & $7.38 \pm 3.35$ \\
\hline TC & ----------- & $6.18 \pm 2.76$ \\
\hline SA & $1.50 \pm 0.59$ & $7.95 \pm 3.11$ \\
\hline TA & ----------- & $4.71 \pm 0.99$ \\
\hline
\end{tabular}

Results expressed as mean \pm stantard; $n=10$ animals per group. SC=sedentary control; TC= Trained control; TA =Trained alloxan; $\mathrm{SA}=$ Sedentary alloxan. (student t-test, at 28 days; two-way ANOVA, at 60 days, $P<0.05$ ).

Table 3: HOMA index (homeostasis model assessment) of the animals at weaning (28 days) and in final experiment (60 days).

BLOOD LACTATE-EFFORT TEST

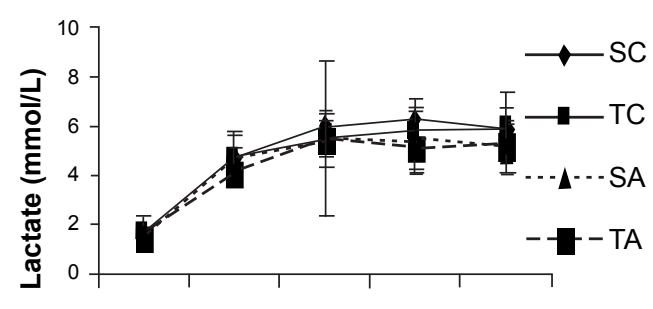

$\begin{array}{lllll}\text { T0 } & \text { T5 } & \text { T10 } & \text { T15 } & \text { T20 }\end{array}$

Time (min)

Figure 4: Blood lactate of the animals during effort test accomplished at the end of training to verify exercise effect. Results expressed as mean \pm standard deviation; $\mathrm{n}=10$ animals per group. $\mathrm{SC}=$ sedentary control; $\mathrm{TC}=$ Trained control; TA =Trained alloxan; SA= Sedentary alloxan. (Two way, ANOVA, P $<0.05)$.

(Figure 2), shows the area under food intake curve food intake from weaning ( 28 days) to the end of the experiment for all experimental groups. No differences were observed among the groups. Water intake of the animals was also registered during the experiment (Figure 2B). Area under water intake curve was higher in sedentary control (SC) than corresponding trained (TC) and similar among the others groups during all experiment.

Fasting glycemia and insulinemia and glycemia and insulinemia 30 minutes after oral glucose overload evaluated at 28 and 60 days of age, are shown in (Table 1 and Table 2).

Fasting glycemia at 28 days did not differ among the groups, while after glucose overload it was higher in the alloxan group (Table 1). At 60 days, fasting glycemia was lower in the trained groups (TA and TC) when compared to the sedentary groups (SA and SC). After glucose overload, the group AS showed higher glycemic values than the other experimental groups (TA and SC) (Table 2).

Fasting insulinemia, at 28 days, was not different among the groups. After 30 minutes a glucose $20 \%$, the alloxan group 
presented higher values than the control group (Table 1). The values corresponding to the fasting insulin at 60 days also were not different among the groups. After 30 minutes of the glucose overload, the trained groups $(\mathrm{TA}$ and $\mathrm{TC})$ presented lower values $(\mathrm{p}<0.05)$ than sedentary groups (SA and SC) (Table 2).

The results of the oral glucose tolerance test (OGTT) performed at 28 and 60 days are shown in the Figures $3 \mathrm{~A}$ and 3B. The results of blood glucose level were evaluated by the areas under their respective curves $(\mathrm{AG})$. The $A$ group presented $A G$ higher values than the $C$ group ( $\mathrm{p}<0.05$ ) (Figure $3 \mathrm{~A}$ ) at 28 days. At 60 days, the $\mathrm{SA}$ group presented the higher AG in relation the other groups (Figure $3 \mathrm{~B}$ ), evidencing the drug effectiveness in altering the glucose homeostasis and the importance of training in counteracting the alteration.

The insulin sensitivity index (HOMA-Index) results are described in Table 3. Although the statistical analysis did not show significant difference among the groups at 28 and at 60 days, it is observed that at 60 days, the values of HOMA-index of the trained groups (TA and $\mathrm{TC})$ were slightly lower of the equivalent sedentary.

The blood lactate concentrations of the animals during the effort test at end of the experiment (60 days) did not differ among the groups (Figure 4).

\section{Discussion}

Since long time there is a strong association between the incidence of type 2 diabetes mellitus and a sedentary lifestyle. In this context, increases in physical activity patterns have thus emerged as an integral part of the prevention and management of type 2 diabetes. Physical training has proved to be an important strategy in the prevention and in the treatment of this disease, improving glucose tolerance and reducing insulin resistance. In this study investigated the effects of moderate aerobic training on the evolution of the diabetic picture in rats submitted to the neonatal alloxan application.

In relation the body weight evolution and body weight gain of the animals, it was observed that the trained groups presented lower values than the sedentary groups, showing the effectiveness of the training protocol in reducing body weight and indicating modulation by exercise of an aspect known to be implicated in the T2DM manifestation.

When analyzed the area under food and water intake curve, the alloxan animals did not show, polyphagia and nor polydipsia, indicating that the neonatal alloxan administration cause a less severe diabetes, as compared to alloxan diabetes induced in adult rats which causes severe polyphagia and polydipsia [18].

The sedentary alloxan group (SA) showed higher blood glucose levels after the glucose overload and higher area under the blood glucose curve during the oral glucose tolerance test (OGTT) in relation to the sedentary control group (SC). These results are similar to those from Kodama et al. [11], Oliveira et al. [12], who analyzed the glycemia of neonatal alloxan treated rats at 60 days old and observed significantly higher values in alloxan groups than in controls groups. This can be attributed to the selective destruction of part of the beta cells [18].

Also, in the present study, after four weeks of aerobic physical training, it was possible to observe that the trained groups, both control (TC) and alloxan (TA), had lower glycemia after the glucose overload and lower area under blood glucose curve during the oral glucose tolerance test, when compared to the sedentary groups. The same was observed in other studies accomplished in trained adult alloxan diabetic rats $[20,21]$. This may be explained by the sinergic effect of the exercise to the insulin action in the control of glucose homeostasis [22]. Even more, studies had shown that there is an upregulation in the mRNA expression as well as in the Glut-4 protein expression in the skeletal muscle of trained healthy rats $[23,24]$. In addition, the increase either in the production of nitric oxide or in the capillary flow to the muscle tissue during exercise contributes to increased glucose disposal from the circulation [25]. Therefore, the reduction in the blood glucose concentration of the trained animals might have been mediated by any one of these mechanisms, separately or together.

Fasting insulinemia of the alloxan and control groups was similar at 28 days, while after the glucose overload it was significantly higher in the alloxan group than in the controls. At 60 days, the fasting serum insulin value also did not show significant difference among the groups. The insulinemia after the glucose overload presented lower values in the trained groups (TC and $\mathrm{TA}$ ) when compared to the sedentary groups (SC and SA). Such results contrast with the results found by Gomes et al. [26] who observed, in a study with adult alloxan diabetic rats, lower insulin values for the diabetic group, evidencing the differences between the type 1 and the type 2 alloxan diabetes models.

In the present study the insulin sensitivity was estimated by the HOMA-index (Homeostasis model Assessment index). Few studies have been accomplished using HOMA-index application in experimental models of alloxan diabetes [27]. This procedure did not identify any alteration among the groups. However, the HOMA index values of the trained animals in both groups were slightly lower than the sedentary groups. For this method, high index denotes low insulin sensitivity (resistance) [16]. Our results regarding the trained groups seem to indicate improvement in the insulin sensitivity in consequence of the training, what is of interest for diabetes mellitus prevention and treatment.

Among the parameters to be considered in exercise programs for the diabetic population, effort intensity has received special attention. For this reason the blood lactate concentrations during exercise are often evaluated, aiming at adaptation the physical training to diabetic patients [28]. Thus, in the present study an effort test was performed to evaluate the exercise effect by blood lactate concentration.

In human beings, during an exercise of low or moderate intensity, blood lactate does not increase anymore after 3 to 5 minutes of activity, returning to resting values when the exercise is prolonged for more than one hour. In this situation, the lactate production is in balance or even lower than its clearance [29]. When high intensity exercises are executed, blood lactate concentration rises after 3-4 minutes of activity [30], is indicating that the production level overcomes removal level. Training reduces the lactate accumulation in blood during exercise for the same submaximal effort intensity, due to the increased removal [31]. The results of lactacidemia obtained in the test accomplished in this study did not identify any difference among groups. An adjustment in the training protocol is required in future studies aiming a better effectiveness of the training protocol in improving the aerobic conditioning of the rats.

On the other hand, the results of the test confirm that the animals performed moderate intensity exercise, since blood lactate stabilized after 10 minutes of exercise. These data also confirms our previous results which demonstrated that in swimming exercised rats, a balance between production and removal of lactate from the circulation (lactate steady state) occurs when the animals are trained supporting overloads equivalent to $5 \%-6 \%$ of the body weight [13]. 
Citation: Ribeiro C, de Alencar Mota CS, Voltarelli FA, de Araújo MB, Botezelli JD, et al. (2010) Effects of Moderate Intensity Physical Training in Neonatal Alloxan- Administered Rats. J Diabetes Metab 1:107. doi:10.4172/2155-6156.1000107

Page 5 of 5

In conclusion the results obtained suggest that this diabetes mellitus animal model presents interesting characteristics for the study of the role of the physical exercise in diabetes outcome.

\section{Acknowledgments}

We are grateful to C.Y. Sibuya, J.R. da Silva e E. Custódio for the excellence the technical support. Financial support from the following agencie: FAPESP (proc: 09/51538-5).

Competing interests: The authors declare that they have no competing interests.

\section{References}

1. ADA (2009) Diagnosis and Classification of Diabetes Mellitus. A position statement of the American Diabetes Association Diabetes Care 32: 62-67.

2. Rossini AA (2004) Autoimmune diabetes and the circle of tolerance. Diabetes 53: $267-275$

3. Brownlee M (2001) Biochemistry and molecular cell biology of diabetic complications. Nature 414: 813-821.

4. Kelly MA, Rayner ML, Mijovic CH, Barnett AH (2003) Molecular aspects of type 1 diabetes. Molecular Pathology 56: 1-10.

5. Hayashia T, Hirano AT, Yamamoto T, Ito Y, Adachi M (2006) Intensive insulin therapy reduces small dense low-density lipoproteinparticles in patients with type 2 diabetes mellitus: relationship totriglyceride-rich lipoprotein subspecies. Metabolism 55: 879-884.

6. Ivy JL, Zderic TD, Fogt DL (1999) Prevention and treatment of non-insulindependent diabetes mellitus. Exerc Sport Sci Rev 27: 1-35.

7. Kelley DE, Goodpaster BH (1999) Effects of physical activity on insulin action and glucose tolerance in obesity. Med Sci Sports Exerc 31: 619-623.

8. Gallen I (2003) Exercise in type 1 diabetes. Diabetic Medicine. 20: 2-5.

9. Zinman B, Ruderman N, Campaigne BN, Devlin JT, Schneider SH (2003) Physical activity/exercise and diabetes mellitus. Diabetes Care 26: 73-77.

10. Portha B, Blondel O, Serradas P, McEvoy R, Giroix MH, et al. (1989) The rat models of non-insulin dependent diabetes induced by neonatal streptozotocin. Diabete Metab 31: 61-75.

11. Kodama, T, Iwase, M, Nunoi K, Maki Y, Yoshinari M, et al. (1993) A new diabetes model induced by neonatal alloxan treatment in rats. Diabetes Res Clin Pract 20: 183-189.

12. Oliveira CAM, Luciano E, Mello MAR (2004) Características do Diabetes Mellitus induzido pela administração neonatal de aloxana em ratos. Bioscience Journal 20: 93-102

13. Gobatto CA, de Mello MA, Sibuya CY, de Azevedo JR, dos Santos LA et a (2001) Maximal lactate steady state in rats submitted to swimming exercise. Comp Biochem Physiol A Mol Integr Physiol 130: 21-27.

14. Herbert V, Lau KS, Gottlieb CW, Bleicher SJ (1965) Coated Charcoal immunoassay of insulin. J Clin Endocrinol 25: 1375-1384.
15. Mathews JNS, Altman DG, Campbell MJ, Royston P (1990) Analysis of serial measurements in medical research. BMJ 27: 230-235.

16. Bonora E, Targher G, Alberiche M, Bonadonna RC, Saggiani F, et al. (2000) Homeostasis model assessment closely morrors the glucose clamp technique in the assessment of insulin sensitivity. Diabetes care 23: 57-63.

17. Engel RC, Jones JB (1978) Causes and elimination of errstic blanks in enzimatic metabolic assays involving the use of NAD+ in alkaline hydrazine buffers: improved conditions for assay of 1- glutamate, 1- lactate and other metabolites. Anal Biochem 88: 475-484.

18. Lenzen S, Panten U (1988) Alloxan: history and mechanism of action Diabetologia 31: 337-342.

19. Pauli JR (2005) Efeitos do treinamento físico sobre aspectos endócrinometabólicos de ratos administrados com dexametasona. IB- Universidade Estadual Paulista - Rio Claro.

20. Gomes RJ, Caetano FH, Mello MAR, Luciano E (2005) Effects of chronic exercise on growth factors in diabetic rats. JEP 8: 16-23.

21. Leme JACA, Silveira RF (2006) Efeitos da atividade física em parâmetros metabólicos de ratos diabéticos. Braz J Sci Mov 14: S99.

22. Zinman B, Ruderman N, Campaigne BN, Devlin JT, Schneider SH (2004) Physical activity/exercise and diabetes. Diabetes Care 27: 58-62.

23. Lee JS, Bruce CR, Tunstall RJ, Cameron-Smith D, Hugel H, et al. (2002) Interaction of exercise and diet on glut-4 protein and gene expression in type I and type II rat skeletal muscle. Acta Physiol Scand175: 37-44.

24. Borghouts LB, Keizer HA (2000) Exercise and insulin sensitivity: a review. Int J Sports Med 21:1-12.

25. Sakamoto S, Minami K, Niwa Y, Ohnaka M, Nakaya Y, et al (1998) Effect osf exercise training and food restriction on endothelium-dependent relaxation in the Otsuka Long- Evans Tokushima Fatty rat, a model of spontaneous NIDDM. Diabetes 47: 82-86.

26. Gomes RJ, Caetano FH, Hermini EA, Rogatto GP, Luciano E (2003) Efeitos do treinamento físico sobre o hormônio do crescimento $(\mathrm{GH})$ e fator de crescimento semelhante à insulina (IGF-1) em ratos diabéticos. Revista Brasileira de Ciência e Movimento 11: 57-62.

27. Jia DM, Fukumitsu KI, Tabaru A, Akiyama T, Otsuki M (2001) Troglitazone stimulates pancreatic growth in congenitally CCK-A receptor-deficient OLETF rats. Am J Physiol Regul Integr Comp Physiol 280: 1332-1340.

28. Belli T, Ackermann MA, Ribeiro LF, Langeani R, Galdino da Silva R, et al. (2007) Lactate and ventilatory thresholds in type 2 diabetic women. Diabetes Res Clin Pract 76: 18-23.

29. Brooks GA (1991) Current concepts in lactate exchange. Med Sci Sports Exerc 23: 895-906.

30. Wasserman K, Beaver WL, Whipp BJ (1986) Mechanisms and patterns or blood lactate increase during exercise in man. Med Sci Sports Exerc 18: 344-352.

31. Donovan CM, Brooks GA (1983) Endurance training effects lactate clearance, not lactate production. Am J Physiol Endocrinol Metab 244: 83-92. 